The Spectrum of

\title{
Energy Innovation Portal Brings DOE Technologies to the Market
}

For venture capitalists, energy entrepreneurs, and industry veterans, finding the right renewable energy or energy efficiency solution used to be like looking for a needle in a haystack. Now, a searchable treasure trove of innovative U.S. Department of Energy (DOE) technologies is available. Created by the National Renewable Energy Laboratory (NREL), the online Energy Innovation Portal helps businesses and entrepreneurs access the intellectual property of DOE's 17 national laboratories and other research partners.

NREL's previous experience with industrial partners led its Commercialization and Technology Transfer Office to identify the need for a comprehensive database of available DOE technologies. Never before had an exhaustive effort been undertaken to show DOE's ouput from a patent perspective.

NREL led the development of the Energy Innovation Portal (techportal.eere.energy.gov) for DOE's Office of Energy Efficiency and Renewable Energy (EERE), creating the architecture and carrying out the software development, including the selection and integration of more than 50 software applications. The Java-based website employs a MySQL relational database and includes a customized content management system and a search engine tuned to meet the needs of investors and entrepreneurs.

NREL also oversaw the initial development of a customized software script-and executed subsequent script improvements - to automatically populate the MySQL database with more than 15,000 DOE-created patents and published patent applications, sourced from the U.S. Patent and Trademark Office. Patents from DOE national laboratories are filed under the names of their managing organizations_-for NREL, it was previously the Midwest Research Institute and is now the Alliance for Sustainable Energy. But for the Energy Innovation Portal, NREL developed an improved algorithm to associate laboratory contract numbers and management organizations to the laboratories themselves, allowing users to find the relevant patents by simply searching for the names of the national labs.

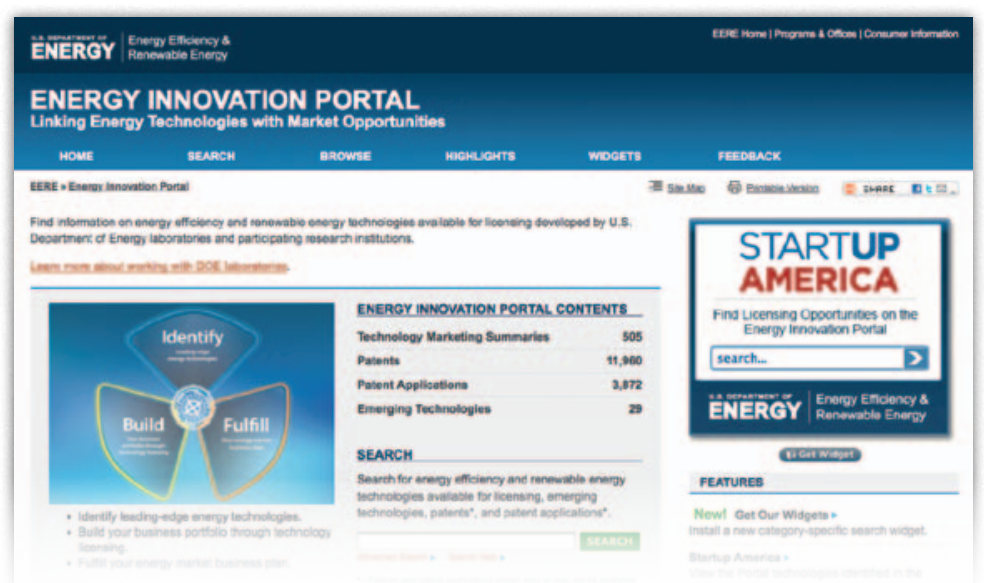

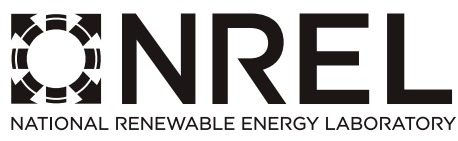

NREL is a national laboratory of the U.S. Department of Energy, Office of Energy Efficiency and Renewable Energy, operated by the Alliance for Sustainable Energy, LLC. 
The portal also provides more than 500 business-friendly market summaries for technologies available for licensing throughout the national labs. In addition to the market summaries, the portal includes summaries of emerging technologies for which the patent applications have not yet been published.

\section{How It Works}

The Energy Innovation Portal gathers patent data by tapping into the U.S. Patent and Trademark Office database and searching the millions of entries for those funded by DOE. Content administrators from NREL or any of the other research partners can then add marketing summaries and summaries of emerging technologies. These help businesses interested in licensing the technologies to understand their potential uses.

"A patent is a legal document written from a legal perspective-what we wanted to do was create and include the marketing summaries written by the labs that tout the technology features, potential applications in the market, advantages, diagrams, and contact info," says Matt Ringer, NREL's program manager for technology commercialization. "You won't see one of these summaries for every patent; rather we wanted the laboratories to be able to highlight the technologies they wanted to focus on, so that technology seekers could find them."

Portal users can search thousands of clean energy related patents available for licensing as well as patent applications; browse marketing summaries of clean energy technologies available for licensing, which are organized into 14 technology areas; see cutting-edge emerging technologies; sign up for e-mail updates; and link directly to the DOE laboratories that developed the available technologies to get more information.

The principle behind the portal is one of collaboration and partnership-public-sector laboratories like NREL need private-sector partners to move inventions to market and deploy them in the global marketplace. The portal supports that public-private collaboration and makes the innovation process as fast and as effective as possible.

\section{Technologies at one's fingertips}

What can be found on the portal? A market summary for Zymomonas mobilis 8b, for one-a genetically designed bacterium from NREL that dramatically reduces the cost and effort involved in producing cellulosic bioethanol. Interested biofuels manufacturers can easily access more information about $Z$. mobilis $8 b$ or contact information for a licensing professional.

Other recent market summaries include a process for converting algal oil to alternative aviation fuel, developed by Los Alamos National Laboratory; a new "Glitter" photovoltaic technology, developed by Sandia National Laboratories; and Facility Energy Decision System Software, developed by Pacific Northwest National Laboratory to quickly and objectively identify recommended energy improvements to facilities.

The Energy Innovation Portal is easy to use, available to anyone, and free of charge. Users simply point and click to find out more about a technology or to connect with a licensing professional at the appropriate laboratory to talk about accessing these technologies.

"Our national laboratories are a major driver of innovation in this country," says Energy Secretary Steven Chu. "By connecting American entrepreneurs with cuttingedge, ready-to-commercialize technologies from the national labs, the DOE Innovation Portal is helping to grow our economy and create the next generation of American jobs."

\section{Technology categories}

The Energy Innovation Portal contains more than 15,000 patents and patent applications, as well as more than 500 marketing summaries, on such topics as:

- Advanced Materials

- Biomass and Biofuels

- Building Energy Efficiency

- Electricity Transmission and Distribution

- Energy Analysis Models, Tools, and Software

- Energy Storage

- Geothermal Energy

- Hydrogen and Fuel Cells

- Hydropower, Wave Energy, and Tidal Energy

- Industrial Technologies

- Solar Photovoltaic Devices

- Solar Thermal Energy

- Vehicles and Fuels

- Wind Energy

\section{National Renewable Energy Laboratory}

1617 Cole Boulevard Golden, Colorado 80401-3305 303-275-3000 • www.nrel.gov

NREL is a national laboratory of the U.S. Department of Energy, Office of Energy Efficiency and Renewable Energy, operated by the Alliance for Sustainable Energy, LLC.

NREL/FS-6A42-50992 • October 2011

Printed with a renewable-source ink on paper containing at least $50 \%$ wastepaper, including $10 \%$ post consumer waste.

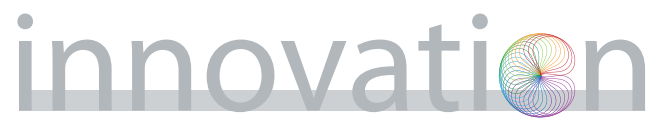

